\title{
ESTÉTICA E FILOSOFIA DO \\ FUTEBOL: Copa do Mundo 2014 em \\ seis crônicas \\ Miguel Gally ${ }^{1}$ \\ gally@terra.com.br
}

\section{Resumo}

Textos publicados informalmente em listas de emails e na rede social digital Facebook durante a Copa do Mundo 2014 de futebol no Brasil, entre junho e julho. Seguindo alguns pressupostos da filosofia da cultura, tais crônicas tentam explorar a dimensão reflexiva implícita no mundo do futebol.

Palavras chave: estética, futebol, reflexão, vida.

\section{Abstract}

Pieces published between June and July during the World Cup Brazil 2014 using email lists and the social network Facebook. Following some ideas of the Philosophy of Culture, these works try to explore the reflexive dimension of the football world.

Keywords: aesthetics, football, reflexion, life.

\section{PARA UMA FILOSOFIA DA HISTÓRIA DO FUTEBOL BRASILEIRO NAS COPAS}

Brasília, um dia antes da abertura da Copa do mundo de futebol de 2014.

Dizem por aí que a copa já começou, ou melhor, que o clima da copa já começou... o clima sim, a copa não! A copa só começa depois do primeiro chute do primeiro jogo. Mas enquanto não começa, acho que dá para pensar no sentido das copas para nós. Foi Nelson Rodrigues quem primeiro imaginou uma espécie de filosofia da história da participação da seleção brasileira nas copas, do seu começo em 1930 até 1978, a última que ele pôde acompanhar. Acho que vale a pena avaliar um pouco as copas posteriores e, quem sabe, comparar com a que começa logo logo, enquanto ela

\footnotetext{
${ }^{1}$ Professor da Faculdade de Arquitetura e Urbanismo da Universidade de Brasília.
} 
não começa mesmo. É, contra todas as previsões, parece que vai mesmo ter copa! Claro, do nosso jeitinho e dentro daquele caos de sempre!

Uma filosofia da história, grosso modo falando, pode ser o sentido que se dá a um percurso passado, de modo a orientar nosso presente como fazendo parte dele ou não, e em alguns casos, tentando prever como seria o futuro. A escolha de qual é tal sentido é sempre arbitrária, sabemos, seja o progresso para algumas ciências, seja a repetição criativa para as artes, etc. Nelson falava do conhecidíssimo "complexo do sentimento de vira-latas", ora aflorando ora desaparecendo ao longo da história das copas. Esse sentimento, para Nelson, era uma relação que os brasileiros estabeleciam com o estrangeiro, pondo o outro sempre como melhor, mais digno, mais verdadeiro, mais correto, enfim mais puro... essa sensação de inferiorização de si se mostrava no medo e no pânico dos nossos jogadores gênios quando entravam em campo. E esse sentimento extrapolava o campo. Para Nelson, a superação desse sentimento negativo acontecia quando enchíamos o peito, quando nos tornávamos "somente peito", altivamente transtornados, afirmativos e orgulhosos de si... o que aconteceu pela primeira vez em 1958, quando o Brasil ganhou a final contra a dona da casa, a Suécia. Mais uma vez, quatro anos depois, enchíamos o peito no Chile, comandados por Garrincha. Depois, esse sentimento de vira-latas teria nos assolado novamente em 1966 durando até 1970, sendo esquecido momentaneamente... e reaparecendo mais uma vez até 1978.

Para Nelson, o sentido das participações da seleção nas copas se resumia a uma oscilação entre dois polos, sentir-se vira-lata ou superar tal sentimento esquecendo-se dele. A coisa é que ele não viu o que aconteceu em 1982 nem em 1998 ou 2006, quando experimentamos sentimentos mais ambíguos, complexos ou medíocres. Nestas copas, um misto de azar e displicência ofuscou aquela história límpida que oscilava entre sentir-se ou não vira-latas. Em 1982, puro azar e sua frustração subsequente. Em 1998, em plena final contra os donos da casa, o time parou e foi dominado por Zidane e companhia, e até hoje se comenta as convulsões do Ronaldo fenômeno e de suas factíveis consequências para o time. Naquela final, fomos sim dominados e ninguém nunca saberá se teríamos ganhado com a força máxima. Era o caso de reconhecer que éramos inferiores naquele momento, não que nos sentíamos assim, um sentimento diferente, sem dúvida. Em 2006, a displicência assolou nossos craques na Alemanha, que estavam mais preocupados consigo e seus recordes; consigo e suas vaidades. Com alma também se jogou aí, mas com a alma pesada e medíocre. Resultado, vivemos 
aquilo que chamei na época de umas das mais terríveis ressacas de copa. Dentro de campo, acredito que pouco se tem visto daquele sentimento de vira-latas nas últimas participações do Brasil em copas, porque hoje todos temem o Brasil e jogando em casa nossa seleção se torna então ainda mais terrível e supostamente imbatível. Entrar em campo com tamanho favoritismo é ruim e difícil, Zico e muitos outros acreditam nisso. Mas pior do que ser ou sentir-se vira-latas, é quando esse favoritismo se transforma em arrogância e passa-se a ter algo que podemos chamar no extremo oposto do complexo de vira-latas de: o complexo do sentimento das raças puras. Um complexo de superioridade e verdade. Por isso, é preciso que o jogo de abertura contra a Croácia comece para sentirmos como estamos. Nenhum amistoso pode dar a ideia do que esses ótimos jogadores podem fazer juntos, incluindo até mesmo a paralisação do medo, por que não? Muitos torcedores estão pessimistas, outros muito otimistas. Todos com razão. Eu prefiro não suspender meu julgamento, chutei 4 x 2 para o Brasil no bolão...

...fora de campo, o Brasil continua o mesmo caos de sempre, ainda pior por causas das obras de infraestrutura inacabadas, oportunismo da propaganda política, arrogâncias e ganância sem fim da FIFA provocando a todos, cambistas vendendo ingressos a $\mathrm{R} \$ 1.500$ e outros absurdos que deixo para outro dia. Hoje, na garagem de uma empresa de transporte urbano do DF, um aviso dizia: “amanhã só haverá ônibus até 15h e depois das 19h!" EH, amanhã é mais do que um feriado...

\title{
II. DESDE QUE SE APRENDEU A GANHAR NO FUTEBOL SEM JOGAR, APRENDERAM QUE APITAR TAMBÉM É JOGAR!
}

\author{
Brasília, 12.06.2014. Brasil 3x1 Croácia.
}

Desde o comecinho do ano eu venho comentando que este é o ano da resenha. Começou com o carnaval, a primeira e, às vezes, a única resenha do ano. Mas 2014 teria ainda a copa e as eleições... seria o ano da resenha das resenhas! Hoje foi o primeiro jogo e o que mais assombrou a todos não foram apenas a arquibancada improvisada, o espetáculo de abertura mal feito, o play back sem vergonha, o boicote da apresentação do exoesqueleto, o índio vestido e com sinto de segurança dentro da canoa, a teimosia de sempre do Felipão, os exageros da polícia fora do estádio ferindo covardemente os manifestantes ou o nervosismo dos primeiros minutos. Nem mesmo o erro de Daniel Alves ou o azar do gol contra de Marcelo. Não. O que ficou exposto e ridículo foi a 
postura do árbitro marcando um pênalti que não existiu e uma falta duvidosa em Júlio Cesar batido. Que a FIFA possa estar por trás disso ninguém em sã consciência pode duvidar. Basta lembrarmo-nos da sua prepotência para conseguir desfazer a proibição legal da venda da bebida dentro dos estádios durante a copa do Brasil ou conseguir a construção de uma corte especial na copa na África do Sul em 2010, quando duas pessoas foram sentenciadas em $48 \mathrm{hs} \mathrm{a} 15$ anos de reclusão. Diante disso não parece ser algo tão complicado favorecer indiretamente um ou dois gols.

A questão, entretanto, não me parece ser a dos absurdos que a FIFA consegue realizar ou do que, fora de campo, se aceitou para sermos a sede desse evento. Agora que a Copa começou, a questão é outra, é honrar o futebol na sua dramaticidade e aceitar a imprevisibilidade do esporte - e isso não pode acontecer manipulando resultados. Não pode ser um vale tudo. Está perdendo a graça. O Brasil anda precisando de uma ajudinha? É isso? Poxa! Não é a primeira vez que isso acontece em Copas. A diferença agora é que somos os beneficiados. Sobre outro resultado manipulado indiretamente como o de ontem, em 1966, entre Argentina e Inglaterra, uma expulsão errada ajudou a baixar o rendimento da seleção argentina e ganhou-se no apito: "como se sabe a Argentina foi miseravelmente roubada. Basta dizer o seguinte: Rattin não fez nada. Simplesmente se dirigiu ao juiz, com uma polidez, uma cerimônia, uma reverência, totais. E o juiz o expulsou. Por quê? Porque era a maior figura da partida. Tinha de sair para a Inglaterra ganhar. E, de fato, ganhou no apito e só no apito" (Nelson Rodrigues, 26/07/1966, O Globo).

A seleção ganhou, mas é aqui não basta ganhar e somar três pontos na tabela. Todos nós sabemos disso, porque abaixo dos pontos conquistados no apito, a sombra da vergonha nos cobre... e lá no fundo, sentimos que faltou algo. Estamos cinicamente aliviados... Muito se perguntou sobre quais seriam as implicações para a propaganda dos partidos políticos se a seleção ganhasse ou perdesse a Copa, L.F. Veríssimo dentre eles (http://www.contextolivre.com.br/2014/06/duas-razoes.html). Talvez a pergunta mais apropriada seja, o que a FIFA perde se a seleção brasileira não for campeã?

Ainda veremos muito mais do que árbitros parciais sendo acusados e suspensos, passaremos agora a ver o invisível e prever o imprevisível: o "Sobrenatural de Almeida" desencantado e aquele "ponta esquerda" que o Veríssimo entende ser o imprevisível... todos eles e muitos outros agora agindo calculadamente e sentando ao nosso lado durante os jogos!!! 
Salve o futebol, salve a teimosia do Felipão, salve o camisa 11, Oscar e sua grande partida de ontem!

\section{A BELEZA DO DRAMA FUTEBOL}

São Jorge/Brasília, 30 de junho de 2014.

Honrou-se a dramaticidade do futebol quando o Brasil bateu o Chile. Mas qual foi o grande drama? O impossível aconteceu. E os chilenos vieram preparados, nada era impossível para eles (http://www.youtube.com/watch?v=aqV-ksOCK5I). E mesmo com o juiz do lado deles e todo seu discurso heroico, a linda trajetória dessa seleção foi interrompida. Onze jogadores conseguiram ganhar de onze jogadores mais um juiz. Não, eu não errei ao incluir o juiz como mais um membro da equipe, um membro especial que tornaria qualquer time imbatível. O Brasil ganhou do Chile e o mais improvável, ganhou do juiz. Vão dizer que se trata de uma obsessão minha criticar a arbitragem. Eu aceito as críticas. E o Robben, camisa 11 da Holanda, está do meu lado; ele assumiu depois da partida contra o México, num gesto moral sem precedente nesta copa, que se jogou e que não sofreu a falta do pênalti marcado nos acréscimos do segundo tempo rasgando a vitória de virada. Mas não nos desviemos do nosso assunto, resta ainda uma pergunta misteriosa. Ganha-se no apito, disso sabemos há muito. Mas como se ganha do apito?

Todos dentro e fora de campo viram um juiz atacante, um juiz meio-campo, um juiz lateral, um juiz jogador onipresente. Perguntem-me como se ganha dos abusos e insanidades de uma arbitragem. Respondo: é só conseguir um Júlio César, um Hulk, um David, um Sobrenatural de Almeida e milhões torcendo ao mesmo tempo. Independente do seu histórico, Júlio César conquistou mais a confiança do torcedor, afinal pegar bolas difíceis e pênaltis exige muito mais do que perfeição técnica. O goleiro precisa estar iluminado, encantado, que o diga o goleiro do México, defendendo ontem até com o nariz. O Júlio estava assim no jogo; ele pode. Hulk foi múltiplo na ponta direita e esquerda, além de defender muito, jogou muita bola; errou, vimos isso no gol do adversário, mas corrigiu seus erros. Perder pênalti não é errar propriamente, é estar para o azar assim como para a sorte e não poder dominar o acaso. Quem em sã consciência diria que Baggio errou ao cobrar mal na final de 1994, ele perdeu a cobrança apenas. Precisamos de um Hulk. David reinou soberano junto com o Tiago Silva, outro rei da 
nossa zaga. E que bom que o imponderável e o improvável estavam em campo também. Essa combinação marcou e honrou o drama do futebol. Doeu, foi difícil e penoso acompanhar e torcer pela seleção, até porque em muitos momentos ela não esteve bem e jogou praticamente sem meio campo. Esse drama uniu tantos brasileiros que muitos se perguntaram depois que tudo acabou sobre o que, de fato, tinha acontecido e tornara o jogo tão difícil de acompanhar até o fim (http://www.cartacapital.com.br/sociedade/otime-e-de-guerreiros-mas-quem-e-o-inimigo-7553.html).

Não há nada de errado com o espírito nacionalista e o vocabulário bélico, porque não há guerra, de fato. Não há inimigo real, tampouco. Se há algum problema em sentir orgulho de sua equipe e de seus colegas, assim como do país ali representado, é o exagero de se acreditar ser maior, melhor ou mais importante do que o outro time/nação; o insurportável é isso. Mas o risco do exagero nacionalista é um risco humano, nada tem a ver com o futebol em particular. No futebol, tudo é uma grande ficção que une as pessoas e recoloca a importância da coletividade, da festa na dor e na angústia. É a ficção de sentir-se mais um em campo, de acreditar que se pode empurrar o time, de fazer o gol com a força da imaginação e de imaginar o que poderia ser se, se, e se... e tudo isso experimentado publicamente... xingando e gritando alto, abraçando, vivendo o drama de cada lance. O nosso foi ter vencido o juiz; conseguimos o impossível e isso não acontece sem deixar marcas. O futebol não é apenas uma partida de futebol, nunca foi. Até para aqueles que não entendem nada de futebol, o futebol guarda algo de estranho e exótico: multidões viverem tão dramaticamente uma partida sem jogá-la de fato. Respeitemos o impossível tornado possível... a beleza do futebol.

\section{UM JOGO DE GOLEIROS}

Brasília, 1 de Julho de 2014.

Terminou Argélia e Alemanha. Vimos muito futebol, finalmente. É claro, nenhum Garrincha, nem um Rivelino ou Zico em campo. Mas certamente duas equipes jogando sem catimba, procurando o gol até o último segundo e arriscando ao extremo. Os goleiros jogaram demais, foram impressionantes. Manuel Neuer jogou quase como um zagueiro, se antecipando em muitos lances.

Isso me fez pensar que esse negócio de futebol moderno no qual os jogadores desempenham pelo menos duas funções ainda não havia chegado para a vida dos 
goleiros. Sim, vimos os atacantes recuando e marcando a saída de bola, já vimos também um meio de campo que tenta se dividir em marcar e criar jogadas, laterais jogando como pontas e zagueiros e zagueiros jogando como volantes ou líberos. Só faltava o goleiro subir para a zaga e hoje vimos um quase como meio campo. Pensando bem, isso poderia ser muito útil para o Felipão, assim precisaríamos de menos um marcando. E assim um mais livre para jogar como meio campo apenas, coisa que ainda não conseguimos - um luxo para o futebol moderno! Hernanes entra, pode ser, mas quem vai segurar a marcação? Charada para o Felipão. Rais M’Bolhi trabalhou muito e os dois gols sofridos não desmereceu seu desempenho. Ele foi brilhante, o melhor goleiro e vou mais longe, o melhor jogador da copa até aqui ao lado de Robben. Imbatíveis. E vem a pergunta: como é, então, que sofreu dois gols?

Essa é, no fundo, a grande lição para pensarmos hoje. O primeiro gol da Alemanha foi um grande improviso, um gol gambiarra! Porque de outro jeito a bola talvez nunca tivesse entrado. Imagina se a moda pega, e os alemães aprendem nosso segredo maior contra toda precisão do cálculo dos toques. Depois desse gol, o jogo mudou... Antes de começar a copa, em uma entrevista coletiva da comissão técnica da seleção brasileira, escutei alguém falar que esta seria uma copa não da resistência física, mas da técnica, ou seja, da habilidade seja do toque de bola seja da criação e finalização das jogadas, porque no fundo todas as equipes vieram muito bem preparadas fisicamente. Os argelinos jogaram muito, marcaram, correram e contra-atacaram com muita precisão: são um grande time. Argélia, foi um grande prazer!! Mas a Alemanha jogou melhor e alguém tinha de vencer... trágico assim, não poderia terminar empate, o que teria sido muito justo!

\title{
V. CAMINHO POR ENTRE RESENHAS E LUTO DO BICHO PAPÃO
}

\author{
Alemanha 7 x 1 Brasil. \\ Brasília/Recife, 11 de Julho de 2014, esperando a Holanda.
}

Alemanha tem um time e um goleiro brilhante. Holanda tem um time e tem Robben. Argentina tem Messi e mostrou que está construindo um time. Brasil nem tem time nem tem um gênio até o momento, embora tenha ótimos jogadores. Nós fomos a zebra das semifinais, queiramos ou não. Hoje ainda é um dia de luto, velórios e enterros, passados mais de três dias depois da catástrofe. Não fomos apenas humilhados, 
massacrados, esculhambados ou derrotados. Foi um caos depois do jogo da última terça-feira: assaltos, saques, arrastão, facadas, brigas, discussões infinitas, aquele caos Brasil de sempre multiplicado pela dor da morte misturada com ressaca. Nenhuma imagem consegue dizer isso, embora tantos memes tivessem tentado.

As oito melhores equipes jogaram nos últimos dias. Foram os holandeses que mereciam estar na final, assim como nós nunca deveríamos ter chegado tão longe. Mas sabemos que não há justiça em futebol. O jogo mais equilibrado até o momento foi Holanda e Costa Rica. Até a sorte e o azar estavam bem distribuídos, cada um tinha seu sobrenatural de Almeida em forma. Robben jogou muito e por todo o campo, impressionante! Essa já é a copa do Robben.N Nossa grande ameaça logo mais. Ele jogou mais do que Messi até o momento. Eu achava, até pouco tempo antes do jogo contra a Alemanha, que o Brasil ainda precisava mostrar que queria jogar bola nessa copa. Acho que mostramos isso, se é que alguma positividade possa ser extraída dos $7 \mathrm{x}$ 1. Saímos caoticamente para jogar depois do primeiro gol sofrido, e mostramos que não nos enquadramos na padronização do futebol marcação. Foram momentos quase de pelada e por isso ninguém acreditava no que via; quatro gols em poucos minutos foi surreal, mas já falaram o suficiente! É trágico dizer isso, mas por mais que o senhor Scolari tenha tentado, não conseguiu dominar o caos dentro de cada jogador. Ele viu, sem acreditar, aquilo que ele chamou de "pane do primeiro tempo" e o que eu chamo de "vontade de jogar", até mesmo contra seu próprio técnico. Até mesmo o Fred conseguiu mostrar isso, pasmem! A prova dessa realidade: o gol trágico e belíssimo do Oscar aos 90 minutos de jogo com um placar kafkiano.

A incompreensão do Scolari foi tamanha que, aos 30 minutos do primeiro tempo, ele desistiu do jogo. Se fosse um comandante de um navio, estaria preso em flagrante. Em entrevista curiosa, nosso técnico afirmou em entrevista pós-jogo ter percebido que estava tudo perdido depois do $3^{\circ}, 4^{\circ}$ e $5^{\circ}$ gols, pois enquanto ele pensava, a Alemanha fazia gols. O drama foi tão imenso e trágico que até hoje, quase três dias depois da morte do bicho papão do futebol, muitos ainda tentam entender, procurar as causas, culpados, e não apenas daquele jogo, mas da CBF e da própria cultura da corrupção que nos assola como cidadãos. Todos opinam, até mesmo dizendo terem visto medo nos rostos dos jogadores. Medo tinham todos do Brasil, isso sim, e uma vontade secreta de bater o grande monstro do futebol, respeitado até mesmo pelos mais ousados até mesmo quando não se mostrava assim. Os alemães conseguiram naquele dia e tiveram seu momento de Golias, embora muitos deles não tivessem entendido 
direito que tinham mesmo ganhado o jogo. A perplexidade deles foi idêntica a nossa incredulidade. Além de tudo, não apenas ganharam, destruíram sem piedade o grande bicho papão do futebol. Salve Carla, identificando o bicho e sua morte. Respekt! E respeitamos nosso luto? É claro que não. Desde o dia 09.07, quando se perguntava se tudo estava bem, ouvia-se pelas ruas como resposta: "Não, está tudo 7 a 1!" E essa foi a origem de mais uma expressão linguística. E a memória dessa derrota, agora presente em todo bom dia (quando ele não estiver bom!), talvez seja o recomeço de uma tradição que estávamos perdendo, a do futebol bicho papão que conquistamos desde 1958. Essa é minha profecia! Não queremos um bode expiatório, queremos sim uma equipe inteira responsável pelo massacre dos 7 a 1, incluindo aí Neymar e Tiago Silva. Essa geração 7 a 1 crescerá com esse trauma e terá o direito consertar tudo sem se vender ao futebol marcação e ao futebol ocupação de espaços que padroniza e homogeneíza a vida do futebol jogado.

Há muito não conseguimos jogar bonito. Já o fizemos um dia, o que é difícil, se pensarmos em nossa tradição de gênios e na exigência que isso implica. O que estamos vendo são equipes parecidas do ponto de vista do preparo físico, da qualidade do toque de bola e do desafio de ter um esquema tático, mantê-lo ou mudá-lo conforme a necessidade do jogo. Tendo isso, todas elas se parecem. Costa Rica mostrou ao mundo um esquema tático quase perfeito contra a Holanda. Mas precisou da sorte ainda. Não teve. O que mais se exige do futebol profissional? Não é emoção e garra de qualquer jeito; não, não basta vontade, porque assim corre-se o risco de vermos um jogo de violência e não de futebol. O futebol pede por uma nova revolução depois da sua homogeneização, esterilização e pasteurização... será que aguardamos o suspiro do último gênio ou sua reinvenção no mundo do futebol? Não sei...

\section{DEPOIS DA ULTIMA PÁ DE CAL E A GLÓRIA DO CAMPEÃO}

João Pessoa, 14 de Julho de 2014.

A copa do mundo de futebol acabou ontem e muito se quis saber sobre a receita do sucesso da Alemanha, a grande campeã batendo a Argentina. O editor chefe da sessão de esporte da revista alemã Der Spiegel publicou ainda na madrugada de ontem para hoje o que ele acredita ser tal receita: “A equipe dos novos campeões do mundo é composta por grandes jogadores, flexibilidade tática, robustez física e técnica brilhante. 
O jogo dos novos campeões do mundo é dominante, enérgico, direto e paciente quando deve ser. Ele não é sempre belo - como há pouco foi quando tinha que ser." (http://www.spiegel.de/sport/fussball/weltmeister-deutschland-kommentar-zu-joachimloew-a-980833.html). Ainda nesse texto o elogio maior é para a trajetória do técnico Joachim Loew que coroa um percurso de quase 10 anos com o título no maracanã. Todos nós vimos o jogo e sabemos que a Argentina fez uma grande partida e poderia ter saído com a copa na mão. O técnico da Argentina viu isso com uma clareza impressionante!

$\mathrm{Na}$ entrevista logo após o jogo, além de reconhecer que sua equipe cresceu ao longo e com a competição, Sabella foi sagaz ao dizer que se sente um dos jogadores e que tem orgulho dos seus companheiros. Percebam, ele se inclui no grupo não como um comandante, mas ao lado e quase que como mais um jogador. O Loew fez a mesma a coisa. Entretanto, não era sobre mais essa virtude desses dois técnicos que eu gostaria de falar hoje. Não. Me preocupa essa busca pela receita do sucesso. O futebol que todo brasileiro espera não combina em quase nada com aquilo que o mestre cuca alemão disse, mas com certeza não se pode discordar dos brilhantes jogadores dessa equipe, individualmente falando sim, o Mueller, o Schweinsteiger, o Neuer, o Klose, o Hummels, Lahm, Goetze e quase todos os outros.

Falou-se descaradamente na imprensa brasileira que a grande virtude dos alemães estava na harmonia da equipe e sua unidade mais do que na habilidade individual. Essa é uma fala ressentida e mentirosa, que parte daquilo que faltou para nossa seleção, coletividade e conjunto. A vaidade dos nossos jogadores foi de um desrespeito sem precedentes com o torcedor. Mas por que ressaltamos no outro o que não temos em nós, não significa que os grandes campeões tenham tudo o que se precisa para uma grande partida. Eu digo. Não há grande futebol sem beleza!

A beleza do futebol está mais presente em lances individuais, no lance do gênio, e Goetze teve seu momento ontem, mesmo tendo sido uma grande jogada coletiva. Sempre esperamos, nós brasileiros e tantos outros torcedores mundo afora, por uma grande jogada. Por isso, essa foi a Copa do Robben, pessoal! Repito agora com toda certeza. Revejam suas jogadas e concordarão comigo! A padronização do futebol marcação e ocupação de espaço nunca barrará o gênio - a ululante subjetivação dentro do futebol. E que beleza foi ver o Robben jogar sem três marcadores fixos no jogo contra o Brasil. Trágico para nós, sim, mas melhoramos muito depois daqueles 7 x 1 ... Agora, jogada a última pá de cal sobre o bicho papão, esperamos, de forma igualmente 
trágica, o impossível, o bom senso dentro da $\mathrm{CBF}$, um técnico jogador, porque jogadores temos para dar e vender. E que valorizemos mais a seriedade e o talento do Oscar!

\section{REFERÊNCIAS BIBLIOGRÁFICA}

RODRIGUES, Nelson. "Voltamos a ser vira-latas" Jornal O Globo, em 26/07/1966. In RODRIGUES, Nelson (Org. Ruy Castro). A pátria em chuteiras: Novas Crônicas de Futebol. São Paulo: Companhia das Letras, 1994, pp. 120-122.

VERÍSSIMO, Luís Fernando. Duas razões. Site de Notícias Contexto Livre, acessado 11.06.2014: http://www.contextolivre.com.br/2014/06/duas-razoes.html.

Revistas on line e sites da Internet: Carta Capital, Der Spiegel e You Tube, acessados entre Junho e Julho de 2014 conforme link no corpo do texto. 